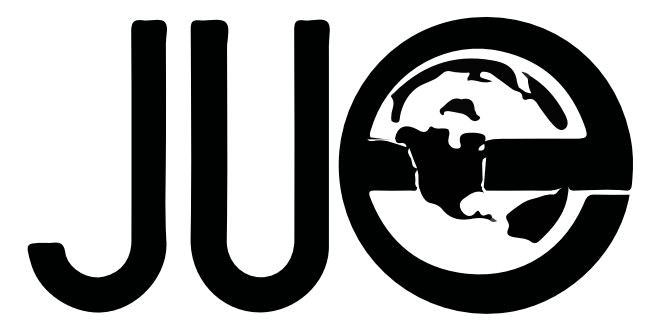

The Journal for Undergraduate Ethnography

Volume 5 | Issue 2

\title{
How Welcoming Space is Created, Maintained, and Always Evolving in Frog Hollow Neighbourhood House
}

\section{Selenna Ho}

University of British Columbia, ho.selenna@gmail.com

\section{ABSTRACT}

his paper uses the theoretical approach of Dorothy Smith's institutional ethnography to analyze the creation, maintenance, and evolving space of Frog Hollow Neighbourhood House. There is a strong focus on how the entrance, users, staff, and funding of the

Neighbourhood House affect the welcoming space of Frog Hollow, with theoretical analysis drawn from Les Back, S.R. Lauer, and Liisa Malkki. This paper concludes that while grant tensions influence the atmosphere of Frog Hollow, it is the users who fundamentally impact the creation, maintenance, and evolution of the overall welcoming space, which is essential to the very existence of the Neighbourhood House. 
"What was your first impression of Frog Hollow when you entered the building?" I asked Jamie, a coordinator of Frog Hollow Neighbourhood House, during our interview. Without a moment's hesitation, Jamie said, “I loved it!” She described seeing a homeless man sitting in the lobby with all of his belongings next to him in a plastic bag. He was having a cup of coffee and she decided to sit down next to him while waiting for her interview. The homeless man told Jamie how much he loved Frog Hollow Neighbourhood House because he was always welcome to enter and have a free cup of coffee. Jamie went on to elaborate:

"I thought 'Wow! --I wanna work here.' It was so great. He just felt so comfortable... Nobody questioned the fact that he had his stuff there, nobody questioned the fact that he came in for the coffee and that's all he wanted. It was just, 'Okay well we have coffee, we have a place for you to sit,' um, and... and that has stayed with me, that sense of welcoming, that... That anybody coming to our front door should feel welcomed and safe in this place... And when he told me that, I thought, 'Wow I really wanna work here.' So, I was really glad I got the job."

Upon hearing this experience that Jamie had over twelve years ago, I began to question, what is it that makes Frog Hollow Neighbourhood House such an inviting environment? I acknowledge that Jamie's encounter with Frog Hollow is not a complete reflection of reality; rather, it involves reflexivity, whereby reality is constructed in dialogue with previous experiences and future expectations, otherwise known as textual implications (Emerson, Fretz and Shaw 1995, 245). In this sense, Jamie's recollection allows her to construct a reality whereby Frog Hollow endorses a warm atmosphere based on her previous and ongoing experiences at the Neighbourhood House. Her construction of this reality is then passed down to those with whom she exchanges this information, including me. At the same time, this kind of description of Frog Hollow's welcoming and warm atmosphere has been told to me many times over by other users of the Neighbourhood
House, which contributes to the constructed reality of Frog Hollow's impact on its users. Perhaps this is a collective narrative of Frog Hollow Neighbourhood House, whereby the experience is co-created through dialogue. Jamie's impression of Frog Hollowi s not isolated to that moment twelve years ago; rather, that welcoming quality seems to have evolved over time to match the feelings and needs of the current and new users (such as me) and staff members of the Neighbourhood House.

This phenomenon is what I will be exploring in my ethnographic paper. How does Frog Hollow Neighbourhood House create, maintain, and develop such a welcoming atmosphere for its users? In order to explore this phenomenon more deeply, I will be guiding the reader through the different processes Frog Hollow employs to develop a welcoming atmosphere -- as an institution and as a space for its collective group of users, staff and funders. I will begin with the entrance at Frog Hollow, then navigate towards the people who use the Neighbourhood House, the staff members, and the grants needed to fund the programs at Frog Hollow. Moreover, to stay true to the idea of welcoming, I aim to write this paper in a style and with a narrative that is accessible to not only scholars and academics, but also to general members of the public.

Dorothy Smith (2005) describes ethnography as "sociology for people" because it is a sociology that starts with our everyday lives and "explores social relations and organizations in which our everyday doings participate but which are not fully visible to us" (1). The process of discovery involves technical and conceptual research that may be outside of the "everyday language experience," but becomes a means of "expanding people's own knowledge rather than substituting the expert's knowledge for our own" (ibid). This intention is parallel with Frog Hollow's deliberate objective of welcoming members of the public, no matter what their background. 


\section{The Importance of Space in Neighbourhood Houses}

The reason I chose to focus on space, more specifically, welcoming space, is because of its significance in the existence of Neighbourhood Houses, which are a kind of place-based community centre (like the settlement house movement in the USA). Sandercock (2009) reflects on the emergence of Neighbourhood Houses as a necessity, as a gathering place for "newcomers and oldtimers" (8). The idea of a Neighbourhood House is based on the idea of "creating a community based on common residency" (9). In other words, a local institution which is meant for everyone in the community, regardless of differences such as ethnicity. Sandercock (2009) describes the Neighbourhood House approach as different from traditional services because it not only meets a need, but it also provides a meeting place where "people can come together and connect through engaging in activities together" (9). Creating a space welcome to all is especially important in Metro Vancouver, where Frog Hollow Neighbourhood House is situated. Metro Vancouver is more multicultural than Miami, Los Angeles, or New York City, with about $51 \%$ of the population being foreign-born (Sandercock 2009, 7).

The needs of community members are numerous, and they can only be recognized, worked on, and fulfilled if the people concerned feel comfortable and welcome towards the Neighbourhood House (Sandercock, Attili, Cavers et al. 2009, 119). The programs and staff of Neighbourhood Houses are the first line of resources for those entering the Neighbourhood House. It is the duty of staff members to ensure that the community members feel welcome enough to use (and possibly continue using) the Neighbourhood House as a means of building community. In this way, Neighbourhood Houses are vital to the construction of a place where there is "genuine acceptance of, connection with, and respect and space for 'the stranger' (outsider, foreigner...)" in relation to the already settled members of the community (Sandercock 2003, xiv).

\section{Methods}

I did my research at the Frog Hollow Neighbourhood House from May to June 2014. I went there once a week for six weeks for two to three hours in the afternoon. I used the Frog Hollow's multipurpose room and did work with the other UBC students and Neighbourhood House's volunteers. We were all preparing for the Pathways Conference (which I will elaborate on later in the paper). As a participant observer, I took descriptive fields notes on site, which included information of who was there, what they were doing, when, why, where, and how. After my work at the Neighbourhood House, I reflected upon my experience with analytic field notes, elaborating on my descriptive notes with sociological and anthropological insights. I also conducted a thirty minute one-on-one interview with Jamie, one of the coordinators of Frog Hollow Neighbourhood House. The information presented in this paper is gathered from my interview and field notes.

\section{The Entrance at Frog Hollow}

At the north west corner of Renfrew and 5th Avenue, right at the \#16 bus stop heading south, stand two seven-foot wooden poles, mounting a five-foot wide and three-foot high sign that says: "Frog Hollow Neighbourhood House. Creating Our Community Together." A logo next to the slogan has blue mountains, green grass, and orange, purple and pink people. The sign is located approximately three feet from the Frog Hollow parking lot, and four feet from the bus stop. The very location and size of this sign make it accessible to people commuting, driving, or walking to Frog Hollow, as well as to those who may have no intention of stopping by the Neighbourhood House, such as people driving or walking by. Perhaps this is a way of attracting future users, or simply a means of solidifying the Neighbourhood House's spot in the community. 
The sign influences the everyday activities of the people who use the space. Dorothy Smith's (2005) concept of a text-reader conversation "recognizes reading a text as an actual interchange between a reader's activating of the text and her or his responses to it... Text-reader conversations take place in real time, in the actual local setting of the reading, and as moments in sequences of action" (288). When people walking by or toward the Neighbourhood House read the sign, they are activating the text by engaging in its material and responding to it in some way.

Those reading the motto, "Creating Our Community Together," which is ultimately the mission statement of the Neighbourhood House, are given an idea of what Frog Hollow aims to do. The staff members and volunteers who use the space are primed for work when they read the sign, because it directs their understanding of what Frog Hollow, as an institution, stands for. The people who enter Frog Hollow as community users will have expectations of what Frog Hollow should be doing, given their own ideas of what "Creating Our Community Together" means.

My own interpretation of the sign has two main points: that Frog Hollow is inclusive; and that the Neighbourhood House is active. It is inclusive because it uses the first-person plural "Our" and "Together," as opposed to "Your". It also uses the words "Creating," which I consider to be an action word. In this sense, by the mere act of engaging in a text-reader conversation with the Frog Hollow sign, the readers are already interacting in the community of the Neighbourhood House, thus strengthening the idea of "Creating Our Community Together."

When I first entered through the doors of Frog Hollow Neighbourhood House, I noticed that along the right wall is a table with a coffee machine, a cup containing stir sticks, a pile of about thirty paper cups, and a 5-inch pile of napkins. There is a sign on the wall behind the coffee maker that says: "We believe good coffee starts good conversations. So stop by and have a cup free coffee and to also have good conversations with other Frog Hollow users. In other words, it is an object coordinating particular activities among particular people.

Text-reader conversations also coordinate a "local and particular course of action with social relations extending both temporally and spatially beyond the moment of the text's occurrence" (Smith 2005, 103). Reading the message displayed on the wall about coffee presupposes organization beyond the text itself. The coffee is "on the house" because it is donated to Frog Hollow by Ethical Bean Coffee. The coffee is meant to encourage those coming to Frog Hollow to keep coming back, because the organization is offering something with monetary value to anybody who comes into the Neighbourhood House. This welcoming includes "homeless person[s]", as Jamie demonstrated in her self-reflection when I interviewed her.

Using Emerson, Fretz, and Shaw's (1995) concept of members' meanings, which involves the researcher looking closely at what members say and do during particular moments, I noted that Jamie emphasized that she and the "gentleman" were both sitting in the lobby of Frog Hollow with different intentions (Jamie's being for an interview; the man's being for the coffee), but they still had something in common: the "sense of welcoming" that they both felt within the space of Frog Hollow. Jamie's first impression of Frog Hollow was constructed by her interaction with the other member within that space (i.e., the "homeless man") (167). She noticed that he felt "comfortable" enough to bring all of his belongings there, while drinking a cup of coffee and knowing that nobody would "question" his presence there.

The above analysis demonstrates the significant role that the sign outside Frog Hollow and the sign in the lobby about free coffee play in creating and maintaining the Neighbourhood House's welcoming atmosphere. The signs on display prime readers to have certain text-reader conversations and therefore certain 
expectations of Frog Hollow, which include: building community, having free coffee, and fostering togetherness. This process, in turn, affects the members' meanings, as exemplified by Jamie and her impression of the "homeless person" drinking the coffee with "nobody question[ing]" him.

\section{The People Who Use Frog Hollow}

Frog Hollow Neighbourhood House provides services and programs that help newcomers settle and integrate with the local community (Sandercock et al. 2009, 115). One such program was the "We Are Strong!: Pathways to a Healthy, Supported Community" project, for which I was a volunteer, called the "Pathways Conference" for short by Jamie and the women organizing the event. The Pathways Conference brings together families to discuss important topics. The three chosen for this year were nutrition, domestic violence, and bullying and isolation. All of the women responsible for this conference were mothers, and most were immigrants. The users of Frog Hollow are attracted to the Pathways Conference because it utilizes what Sandercock (2009) refers to as the "Neighbourhood House approach" (9). The services that Frog Hollow provides, such as the Pathways Conference, are meant to meet a need and create a place where "people can come together and connect through engaging in activities together," as I will explain and illustrate (Sandercock 2009, 9). Also, Frog Hollow is "neighbourhood-based," meaning that it is easily accessible to people living in the neighbourhood. Frog Hollow is next to a bus stop, has free parking, is also next to an elementary school, and many of the users, such as Yvy and Sary, live within close proximity.

Yvy and Sary are the women volunteers with whom I had the most direct contact with over my six-week volunteer placement. The two of them used the space of Frog Hollow to their advantage by bringing up their struggles of never being "fully Canadian." As Yvy and Sary said the first time I conversed with them (and repeated throughout my interactions with them),
"Even though I now have a Canadian citizenship, I still feel like I am not Canadian." Yvy and Sary confessed that they needed an outlet to express themselves, since they seldom had the chance to interact with adults when at home. In pursuit of their members' meaning, through interviews and participant-observation (Emerson, Fretz and Shaw 1995, 167), I found that both of them consider themselves to be immigrants, despite the fact that they have full Canadian citizenship status. Yvy and Sary realize that their status as immigrants will never truly disappear, because their non-White skin colour and their foreign accents will continue to distinguish them as immigrants.

At the same time, they realize that their Canadian citizenship status also gives them the privilege of bringing some of their family over to Canada to live with them and "start a new life." The discourse of "immigrant" and "Canadian citizen" identifies the ways with which these women undergo institutional capture (with the institution in question being the Canadian state). Smith (2005) describes institutional capture as the institutional discourse that can subsume subjective experiences, which can happen when both the informant and the researcher "are familiar with institutional discourses, know how to speak it, and hence can easily lose touch with the informant's experientially based knowledge" (225). Institutional discourse "swallows the perspective... and the subjective experiences" of individuals (156).

For instance, Yvy and Sary, both classified as Canadian citizens, have the advantages that come with being a Canadian citizen, including the right to apply to bring over some family members from their native countries to Canada, as well as the right to have their children who are born in Canada classified as Canadian citizens. However, becoming a Canadian citizen also has disadvantages, which includes the loss of free Canadian settlement services, such as language assessments and classes; help finding a job; and information about community services. Institutional capture does not recognize the fact that both Yvy and Sary both feel not 
fully Canadian, as the institutional discourse does not identify with their individual experiences.

With these disadvantages, Yvy and Sary reach out to Frog Hollow Neighbourhood House as a means of institutional freedom, where they can temporarily be free from institutional capture. Their legal status as Canadians and self-identification as immigrants, as well as their motherhood, give them access to programs at Frog Hollow that specifically cater to that group, such as the Pathways Conference. Moreover, their experiences of feeling non-Canadian yet having the status of non-immigrant are unique, and not recognized within the institutional discourses that process their Canadian statuses. Going to Frog Hollow allows these women to navigate these exclusionary experiences and find new ways of inclusion precisely because Frog Hollow is a Neighbourhood House dedicated to the needs of the people in the community. This process with Frog Hollow, in turn, allows them institutional escape (Smith 2005, 123).

The Pathways Conference also allows Yvy and Sary to connect with other women who also identify as immigrants even though they have Canadian Citizenship. Despite these opportunities, Yvy and Sary seem to connect the best with each other, because they were born in the same country, and they often compare stories of their homeland with one another. S.R. Lauer and M.C. Yan (2010) state that "research on homophily (the similarity of personal ties) and associations has found associations often attract members with similar characteristics, thereby contributing to the homogeneity of social networks" (133). In this sense, Frog Hollow Neighbourhood House has coincidentally fostered an ethnically homogenized social relationship between Yvy and Sary through their participation in the Pathways Conference. Liisa Malkki (1997) suggests that "identity is always mobile and processual," that the roots of one's identity are "in a state of constant flux and change... [and] don't stay in one place" (37). Using this analysis, Yvy and Sary have a deep connection precisely because they have struggles transitioning, both physically and mentally, from being immigrants to being Canadians. Their identities are transforming and adapting to their new way of life. The shift in identity from being citizens of their country of birth, to being immigrants to Canada, and now Canadian Citizens highlights the "multiplicities of attachments that people form to places through living in, remembering, and imagining them" (Malkki 1997, 38). Because Yvy and Sary share significant similarities, they are closer with one another than with the other women of the group.

For instance, Yvy and Sary often reminisce together about growing up in their homeland. Both of them grew up on farms. They talk about the crops, the weather, household chores, and what their family members were like. They talk about going to the mall during their free time --not because they wanted to buy things, but because it was the only place nearby with free air conditioning. This conversation will then transition into their current life in Canada, where both have just become mothers, and the difficulties that come with being a Canadian citizen but still identifying as a citizens of their country of origin. "I need to improve my English" they often state, as a means of solidifying their new Canadian identity.

At the same time, I must critique my theoretical observations because I only conducted six sessions of fieldwork over six weeks for the Pathways Conference. Also, during those six sessions, Yvy and Sary were the mothers who came in to the drop-in sessions for the Pathways Conference the most often. However, the analysis of their members' meanings show that the two have a special bond due to their ethnic and geographic similarities, as they are both from similar areas of their homeland, and they live quite close together in Canada. These commonalities lead them to share personal ties and stories that the other women are not able to. That said, my theoretical observations are still limited by the time allotted and actual interactions I had with the women in the Pathways Conference. 
As Les Back (2007) states, "without a certain kind of space, a certain kind of story is simply impossible" (51). In this sense, the users of Frog Hollow maintain its welcoming atmosphere by participating in it and creating their own open space, where they can discuss sensitive issues and escape from the institutional captures of their everyday lives. For instance, during my term at Frog Hollow Neighbourhood House, I interacted with several mothers who prepared a presentation on the topic of domestic violence. In order to discuss this controversial and sensitive topic, they created a warm environment by smiling, translating for one another so that nobody was left out of the conversation, and thanking each person for her effort and contribution to the presentation.

To further elaborate, I will use Dorothy Smith's (2005) concept of standpoint, which is a methodological alternative starting point to the "objectified subject of knowledge of social scientific discourse" (288). From the standpoint of the women I interacted with, it is crucial to have a welcoming atmosphere in order to preserve the safe space in which they can discuss sensitive topics. The women who are attracted to the Pathways Conference are those who are interested in analyzing sensitive issues because they themselves have experienced things such as domestic violence and isolation. As a result, the welcoming and warm atmosphere that I experienced at Frog Hollow is maintained by the users of the space precisely because it is what they need in order to work on their projects and, even more importantly, to build connections with one another.

\section{The Staff and the Tension of Grants}

It is also critical to analyze the ways with which the users of Frog Hollow Neighbourhood House interact with the staff members, and how this relationship is an integral feature of the welcoming atmosphere that is fostered. I will be referring to my interview with Jamie, the Neighbourhood Houses Coordinator at Frog Hollow Neighbourhood House. As shown in the introduction.
Jamie emphasized the feeling of welcome and safety she felt when she interacted with the "homeless man" who just wanted a "free cup of coffee."

Jamie's first impression of Frog Hollow has stayed with her for the last twelve years that she has been working at the Neighbourhood House. Her reflections on the experience constructs a reality (Emerson, Fretz and Shaw 1995, 245), whereby this interaction was the catalyst that made her "really want to work" at Frog Hollow . With this constructed reality, Jamie has motivation to continue working at Frog Hollow and to maintain its welcoming quality. As a Neighbourhood Houses Coordinator who has been with Frog Hollow for over a decade, Jamie uses her work knowledge, member's meaning and standpoint to contribute to the overall creation, maintenance, and evolution[OR development] of Frog Hollow's welcoming atmosphere. I will begin by analyzing Jamie's work knowledge, which includes her experience of her own work, and her coordination of her work in relation to other people (Smith 2005, 151).

Jamie explained to me the process that the Frog Hollow staff goes through to ensure that they are staying true to their vision of being "always inclusive" and to look at "what it means to be diverse, to be welcoming." This process involves multiple meetings and staff getaways where the staff learn to work together. She emphasized that the staff "are always looking at a way to improve. [The staff] never relaxes [because Frog Hollow can] always be better." In this work environment, Jamie's work knowledge includes the need to improve in order to better provide for the community, which results in feelings of inclusion and open-mindedness. By working with a staff team that endorses similar values, Jamie has the extensive knowledge built on adapting to the new needs of the Neighbourhood House as the years progress and the users and staff members change (Smith 2005, 149). 
In order to work closely with the users of Frog Hollow and to understand their needs, Jamie constructs meaning through her interactions with those people, and uses these interactions to interpret her own thoughts and organize action that she believes will enhance the Neighbourhood House, which shows members' meanings (Emerson, Fretz and Shaw 1995, 167). From my experiences with Jamie and the Pathways Conference, I noticed that she always referred to the volunteers as "mothers," rather than "women," "volunteers," or the like. By categorizing these Neighbourhood House users as "mothers," Jamie is able to better understand why the Pathways Conference is integral to the volunteers, as they address familial concerns such as nutrition for children, and how domestic violence affects families (134). Moreover, all of the volunteers were either stay-at-home mothers, or immigrant mothers, who lived by the Neighbourhood House and had the free time to create and develop the Pathways Conference. Others who were aware of the program and did not identify as mothers were invited to participate (for instance, UBC students). However, this group usually included the fathers, who worked full-time during the day and therefore could not commit to the Pathways Conference. As a result, the categorization of "mothers" also represented those who not only had the knowledge of familial concerns, but also the resource of time. This constructed meaning, in turn, affects Jamie's standpoint, which is her subject position in the local particularities of bodily existence (Smith 2005, 288). From her standpoint of being a mother, she is able to empathize and relate to the mothers and therefore become engaged in their conversations. Moreover, positioning her standpoint as a mother during the Pathways Conference allows Jamie to regard herself and to have others perceive her from an equalizing discourse, as opposed to positioning herself as a "staff member" or a "user," which does not carry the same connotations in regards to empathy and capacity to relate to others. From her standpoint of being a Neighbourhood House Coordinator, she understands how the Pathways Conference is significant to the families who attend the event and generate and take in the messages around nutrition, abuse, and isolation. From her work knowledge, she uses her skills to help create an environment whereby the women participating in the conference will feel welcome and safe enough to contribute their own input.

At the same time, Jamie's standpoint of being a Neighbourhood Houses Coordinator at Frog Hollow allows her to make visible the "extraordinary complex of the ruling relations" (Smith 2005 , 288). Ruling relations are the institutional complexes that coordinate everyday administrative work and those lives "subject to administrative regimes" (227). In the case of the Pathways Conference, Jamie realizes that in order to run the program, she must continue "looking for funding" because Frog Hollow "never has enough" funding. In order to apply for funds, part of Jamie's job requires that she keeps "a ton of statistics" that prove to granting bodies that certain programs, such as the Pathways Conference, are worthwhile for the people who participate in them and that these programs should be funded.

This very part of our interview highlights the barriers that come with ruling relations that "coordinate the everyday work of administration and the lives of those subject to administrative regimes," relying on textually based realities (Smith 2005, 227). In this sense, the grant applications are the textually-based realities that need to be written and sent off by staff of Frog Hollow Neighbourhood House. These documents coordinate the everyday workings of Frog Hollow users because they are essential in running the programs and projects that Frog Hollow administer, as they provide the monetary funding needed to keep the organization in operation. Jamie acknowledges that this is a barrier for Frog Hollow, because the funding provided determines the quantity of resources that they can secure for a project. Moreover, if there is not enough funding (i.e., they do not get the grant, or only receive a small amount of the grant), then a program may not even be able to run. 
With the reality of ruling relations making programs vulnerable, Frog Hollow is under a fascinating tension. Going back to the Pathways Conference example, Jamie's job requires that she proves the value that this conference has to the neighbourhood. In order to do this, she uses her work knowledge and standpoint to connect with the users of the Neighbourhood House who are involved with this conference, by ensuring that they feel welcome and safe. The welcome and safe atmosphere is further encouraged by the mothers who are participating in that space, because they need those attributes to discuss the sensitive topics of their lives. Only when these events occur, and the popularity and usefulness of the Pathways Conference is shown, is Jamie able to apply for the grants that are the textually-based realities needed to run the program sufficiently, and for the upcoming years. In other words, these ruling relations coordinate the everyday workings of Frog Hollow and those subject to it, including the staff members, volunteers, and users of Frog Hollow.

\section{The Conclusion: Space Within Frog Hollow}

The mission of Frog Hollow Neighbourhood House is to be flexible and multi-service, which reflects its vision of addressing neighbourhood needs in order to build and strengthen community, including its staff members, users, volunteers, and neighbourhood partners. The major challenge that Frog Hollow faces is in raising "public awareness of the vital role they perform, in order to attract more funding for what they do" (Sandercock, et al. 2009, 120).

A critical point that I must make is that although the lived experiences of users are regulated by the ruling relations of those textually-based realities that obtain funding, that does not mean that the welcoming atmosphere within Frog Hollow is inauthentic. The very need to apply for grants stems from the fact that people in the community continue to feel a need for specific programs, such as the Pathways Conference, at Frog Hollow. The welcoming atmosphere may be influenced by the textually-based realities, but that is as far as it goes. The welcoming atmosphere, I argue, stems from those people attracted to the Neighbourhood House and their everyday doings and lived actualities. Jamie, on her first impression of Frog Hollow, interpreted the interaction she had with the "homeless man" as a sign of the Neighbourhood House's openness, and from what I can ascertain, she has dedicated herself to fostering the warmth that she then felt and still feels. This kind of attraction is not coordinated by the ruling relations; rather, it stems from members' meanings and how they interpret people and events (Emerson, Fretz and Shaw 1995, 168).

Yvy and Sary, upon learning about the Pathways Conference, used it as a means of going around the exclusionary experiences created by institutional capture, which in turn allowed them institutional escape, where they discussed the sensitive topics involved in their lives (Smith 2005, 225). These topics of domestic violence, isolation, and nutrition required a welcoming atmosphere in order to preserve the safe space for discussion of such sensitive topics. By starting from the everyday experiences of people as subjects, rather than objects, the significance of the standpoint of the women who are attracted to the Pathways Conference becomes clear from my ethnographic fieldnotes: they are interested in analyzing sensitive issues because they themselves have experienced things such as domestic violence and isolation (Smith 2005, 288). For instance, Yvy and Sary often mentioned that staying alone in their houses with children made them feel isolated their mother tongue and English. Yvy also shared with me the abuse she went through with her ex-husband, and how many of the other women participating in the Pathways Conference also experienced multiple forms of abuse from their family members.

The concept of homophily is useful in this analysis, as it shows how members with similar characteristics are contributing to the homogeneity of social networks (Lauer and Yan 2010, 133). At this moment, the users of the Neighbourhood House include mothers who identify as immigrants but who also have either 
permanent resident or Canadian citizen status. This similarity breeds trust among them, as they have experiences that they can relate to, and can lend support to one another in their circumstances (135). This theory of homophily can help explain why the users of the Pathway Conference share foundational attributes: they are mothers who are attracted to the ideas that the conference will discuss, and who continue volunteering at the Pathways Conference and Frog Hollow Neighbourhood House because they have created strong social ties with other people there. These bonds are a result of specific similarities, including motherhood and conflicting Canadian and immigrant identities.

It is then a part of Jamie's job as a Neighbourhood House Coordinator to use her work knowledge to observe the significant effects that the Pathways Conference has for the mothers, and to use these insights to enhance the overall experience by having Frog Hollow adapt to the needs of the users (Lauer and Yan 2010, 151). Her insights are understood by her interaction with the users of the Neighbourhood House and how she interprets them into her own member's meanings. By adapting to the needs of the users of the space, the atmosphere within Frog Hollow evolves to continue to be welcoming for those members. It is integral for the space to evolve, in order to complement the needs of its users (Back 2007, 51).

As the staff members, volunteers and users of the space create, maintain and develop this welcoming and safe space throughout the Pathways Conference, they clearly place a high value on it. This value is seen in how members construct meaning through interactions with other members of the group and are able to have institutional escape and share the experiences of their standpoints, as exemplified by Yvy's and Sary's interaction with one another, as Canadian Citizens who identify as immigrants with children. This value is also constructed by how members interact with the space around them, such as the homeless man coming in to have a free cup of coffee.
In order to keep this space for current and future members of the Pathways Conference (and similar programs), funding must be secured. The textually-based realities of grants needed to keep the space running requires that its users maintain the welcoming and safe space. The maintenance is kept through small yet meaningful actions, such as the provision of free coffee, and the bigger actions of mothers grouping together to share past experiences and learn from one another. At the same time, this space has to constantly evolve to match the needs of the new members using the Neighbourhood House. Because the evolution of space is determined by its members, Frog Hollow has to keep a welcoming atmosphere in order to encourage its users to keep coming back and to raise awareness of its programs. With this constructed cycle, the welcoming atmosphere of Frog Hollow is essential to its very existence as a Neighbourhood House serving the needs of its local diverse community. 


\section{Acknowledgements}

Special thanks to all the people I was lucky enough to work with at Frog Hollow Neighbourhood House - the experiences I had there were unforgettable! Also thanks to Heather Holroyd and Negar Hooshmand who helped me write and edit this paper.

\section{References}

Back, Les. 2007. Home From Home. The Art of Listening, 51-70. Oxford and New York: Berg.

Emerson, Robert M., Rachel I. Fretz, and Linda L. Shaw. (1995). Writing Ethnographic Fieldnotes. Chicago, USA: The University of Chicago Press.

Lauer, S.R., and M.C. Yan. 2010. Voluntary Association Involvement and Immigration Network.

International Migration, 5(3), 133-150.

Malkki, Liisa. 1997. National Geographic: The Rooting of Peoples and the Territorialization of National Identity Among Scholars and Refugees. Cultural Anthropology. In A. Gupta and J Ferguson (Eds.), Cultural Power Place: Explorations in Critical Anthropology, 52-74. Carolina, USA: Duke University Press.

Sandercock, Leonie. 2003. Cosmopolis II: Mongrel Cities of the 21st Century. New York: MPG Books.

Sandercock, Leonie. 2009. From Nation to Neighbourhood: Integrating Immigrants through Community Development Plan. Canadian Institute of Planners, 6-9.

Sandercock, Leonie, Giovanni Attili, Vale Cavers, and Paula Carr. (2009). What Is a Neighbourhood

House? Where Strangers Become Neighbours,115-122. New York, NY: Springer.

Smith, Dorothy E. 2005. Institutional Ethnography: A Sociology for People. Lanham, MD: AltaMira Pre

\section{ENDNOTES}

1. Names of people and certain job positions have been changed to protect confidentiality; the real name of the Neighbourhood House (Frog Hollow Neighbourhood House) is used with permission

This work is liscensed under a Creative attribution NonCommercial NoDerivs

3.0 Unported

License. 